\title{
ICT-Based Comprehensive Health and Social-Needs Assessment System for Supporting Person-Centered Community Care
}

\author{
Myonghwa Park ${ }^{1}$, Eun Jeong Choi ${ }^{1}$, Miri Jeong ${ }^{1}$, Nayoung Lee ${ }^{1}$, Minjung Kwak ${ }^{2}$, Mihyun Lee ${ }^{3}$, \\ Eun-Chung $\mathrm{Lim}^{4}$, Haesung $\mathrm{Nam}^{5}$, Dongil Kim${ }^{6}$, Hanwool $\mathrm{Ku}^{6}$, Bong Seok Yang ${ }^{2}$, Junsik $\mathrm{Na}^{7}$, \\ Joong Shik Jang ${ }^{7}$, Ji Young Kim ${ }^{7}$, Wonpyo Lee ${ }^{8}$ \\ ${ }^{1}$ College of Nursing, Chungnam National University, Daejeon, Korea \\ ${ }^{2}$ Research Institute of Nursing Science, Chungnam National University, Daejeon, Korea \\ ${ }^{3}$ College of Nursing, Daejeon Health Institute of Technology, Daejeon, Korea \\ ${ }^{4}$ Graduate School of Public Health, Seoul National University, Seoul, Korea \\ ${ }^{5}$ Department of Preventive Medicine, School of Medicine, Chungnam National University, Daejeon, Korea \\ ${ }^{6}$ Department of Computer Science and Engineering, Chungnam National University, Daejeon, Korea \\ ${ }^{7}$ Mindlle Health Welfare Social Cooperation, Daejeon, Korea \\ ${ }^{8}$ Social Economy Institute, Daejeon, Korea
}

Objectives: This study developed an information and communication technology (ICT)-based comprehensive health and social-needs assessment (CHSNA) system based on the International Classification of Functioning, Disability, and Health (ICF) with the aim of enhancing person-centered community care for community residents and supporting healthcare professionals and social workers who provide healthcare and social services in the community. Methods: Items related to a CHSNA tool were developed and mapped with ICF codes. Experts validated the CHSNA system design and process using the Delphi method, and a pilot test of the initial version of the system was conducted. Results: The following three steps of CHSNA were embedded in the system, which had a user-friendly screen and images: basic health assessment, life and activity assessment, and in-depth health assessment. The assessment results for the community residents were presented with visualized health profiles, including images, graphs, and an ICF model. Conclusions: The developed CHSNA system can be used by healthcare professionals, social workers, and community residents to evaluate the reasoning underlying health and social needs, to facilitate the identification of more appropriate healthcare plans, and to guide community residents to receive the best healthcare services. A CHSNA system can improve the implementation of standardized terminology utilizing the ICF and the accuracy of needs assessments of community residents.

Keywords: Community Health Services, Needs Assessment, Information Technology, Patient-Centered Care, Decision Support Techniques

Submitted: June 20, 2019

Revised: 1st, September 6, 2019; 2nd, October 19, 2019

Accepted: October 19, 2019

\section{Corresponding Author}

Eun Jeong Choi

College of Nursing, Chungnam National University, 266 Munhwa-ro, Jung-gu, Daejeon 35015, Korea. Tel: +82-42-580-8407, E-mail: non5427@naver. com (https://orcid.org/0000-0001-9570-8340) 


\section{Introduction}

The duties associated with elderly care are changing from being performed by the healthcare system to the elderly themselves interacting with social networks $[1,2]$. Increasingly, the location of care provision is moving from the hospital to the community [3]. The government of Korea has addressed this situation at the national level by establishing a new paradigm for the healthcare delivery system, called 'community care. The community-care system provides community residents with care services in the place where they have been living for their lifetime and provides them with appropriate residences, convalescence, care, and independent life so that they can still socialize with the members of their community [4].

The disabled and the elderly have unmet needs for health and social services [5], and allowing them to live in the community means that their needs have to be met based on appropriate assessments. However, this is hindered by healthcare professionals tending to focus on their medical needs, and social workers assessing mainly their social needs. This segmented approach results in community residents receiving provider-centered care services weighted toward either healthcare or social services [6]. The use of a comprehensive health and social-needs assessment (CHSNA) system based on information and communication technology (ICT) and designed to help service providers and community residents can improve the efficiency of the care process by enabling more accurate determination of needs, the identification of more suitable care plans, and the implementation of the best health and social services.

A comprehensive assessment tool is required for the assessment of specific health and social needs. The comprehensive International Classification of Functioning, Disability, and Health (ICF) is not associated with particular health problems or diseases, and it explains the related functioning perspectives from multiple viewpoints at the body, individual, and social levels [7]. Using this framework to design a CHSNA tool represents an affordable way to evaluate the diverse needs of community residents. We therefore developed a CHSNA system based on ICT using the ICF framework with the aim of improving health and social-care services.

\section{Case Descriptions}

\section{Process of CHSNA System Development}

The available literature and guidelines were analyzed and used to identify the components of the CHSNA system developed in this study. We only included articles published in peer-reviewed journals, guidelines, and government report written in English and Korean; therefore, conference proceedings, trial registries, theses, and dissertations were not involved. The publication date was limited to identify the recent relevant studies published since 2010. The initial search terms were 'community care', 'integrated care', and 'aging in place.' The related terms were 'visiting healthcare services', 'care management', and 'community health needs'. The electronic databases used were PubMed/MEDLINE, CINAHL, Cochrane Library, Google Scholar, and the National Assembly Library of Korea. The studies included the general process of community care services, care management and visiting healthcare services, and the instruments used in assessing the needs of community residents. In addition, we conducted a needs analysis for the target users-community residents, healthcare professionals, and social workers-using self-reported questionnaires and interview questions to determine the elements required in a comprehensive assessment system.

The CHSNA system aimed to utilize ICT to facilitate evaluations of the various needs of community residents and to improve the connection between healthcare and social services. The specific objectives were (1) to effectively enhance the assessment process with a user-friendly ICT design and (2) to allow community residents and healthcare profession-

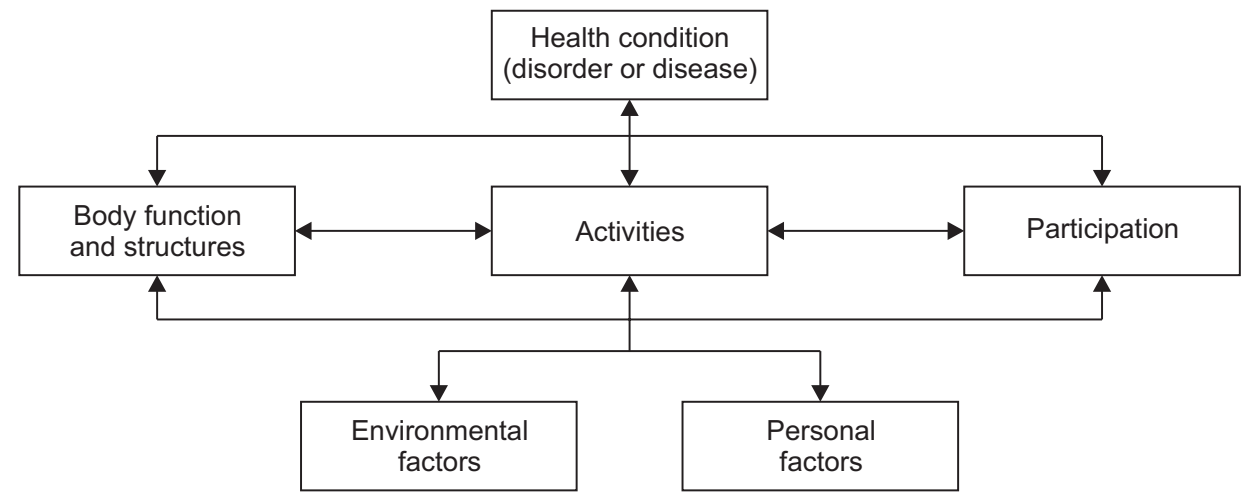

Figure 1. The International Classification of Functioning, Disability, and Health (ICF) model applied to the comprehensive health and social needs assessment system. 
als or social workers to share decision-making when assessing various needs and selecting the appropriate services.

The CHSNA system was developed mainly based on the ICF, which has complex interactions among its components (Figure 1). The items of the CHSNA system include various officially used instruments: (1) the World Health Organization (WHO) Disability Assessment Schedule II [8] and its Korean version [9], which are useful assessment instruments developed by the WHO to assess health and disability levels across cultures; (2) impairment questions based on the Multi-Country Survey Study [10] and WHO world health surveys [11], which aimed to obtain a better understanding of various dimensions of health and health systems and acquire comparable data among countries [12]; (3) a care management manual for Koreans; and (4) a community residents needs assessment for Koreans.

All items of the CHSNA system were mapped onto ICF components based on the available literature [13] and an expert consensus (Figure 2). Thirteen experts on medicine, nursing, public health, social welfare, and occupational therapy participated as the expert group. The algorithm of the CHSNA system was designed based on the care management of social workers and visiting healthcare services of the Ministry of Health and Welfare in Korea.

\section{Implementation of CHSNA System}

The initial version and final version of the system were test- ed by experts from nursing, social work, public health, medical engineering, computer science, and community residents in a city. They applied the system with PCs (laptop and desktops) and mobile devices (tablets and mobile phones). Their opinions formed the basis for several improvements to the system. They evaluated the system usability and design, and offered their opinions. The Institutional Review Board of Chungnam National University approved this study (IRB No. 201809-SB-128-01). All participants provided written consent before the tests were initiated.

\section{Features and Advantages of CHSNA System \\ 1) CHSNA system based on the ICF framework}

The interface of the developed CHSNA system included the following three assessment steps (Table 1). All items of CHSNA were mapped to ICF codes, and the assessment results were expressed as ICF codes and the ICF framework automatically.

All of the developed items were validated by experts using the content validity index (CVI). The CVI values for the items ranged from 0.77 to 0.94 . All items were mapped onto ICF codes, and the validity of the mapping was evaluated by experts.

2) Designing a user-centered CHSNA system

The CHSNA system presents user-friendly icons and images on the screen to help the users comprehend the meaning

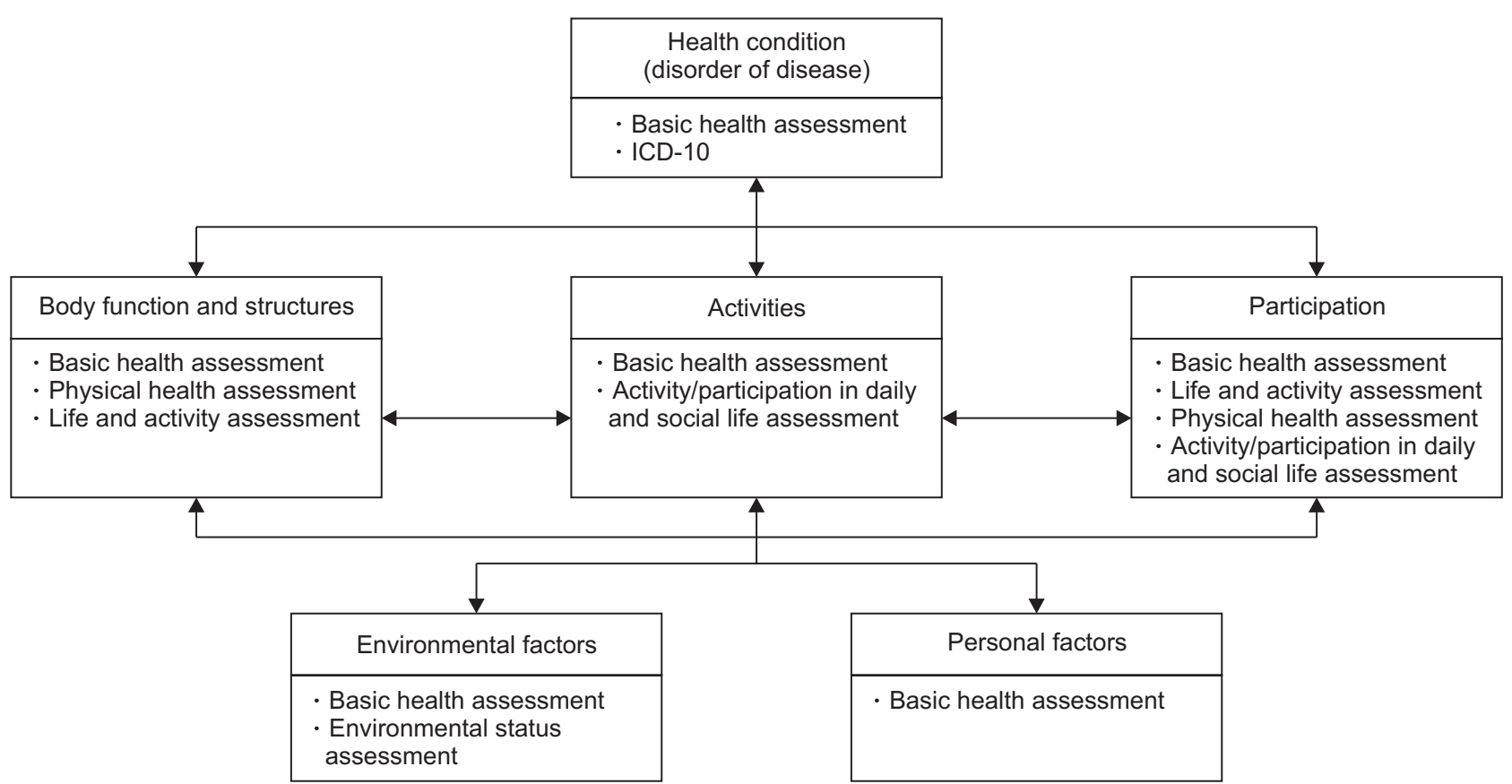

Figure 2. The International Classification of Functioning, Disability, and Health (ICF) model application of the comprehensive health and social needs assessment system in this study. 
Table 1. Contents of the three assessment steps

\begin{tabular}{|c|c|}
\hline Assessment step & Contents \\
\hline \multirow[t]{9}{*}{ Basic health assessment } & Demographic information \\
\hline & Household information \\
\hline & Healthcare and social-welfare services \\
\hline & $\begin{array}{l}\text { Health behavior information, such as smoking, drinking, exercise, and } \\
\text { nutritive conditions }\end{array}$ \\
\hline & $\begin{array}{l}\text { Basic health status, such as height, weight, blood pressure, blood sugar, } \\
\text { and chronic illness }\end{array}$ \\
\hline & Disability and brace usage \\
\hline & Care needs \\
\hline & Subjective health status \\
\hline & Self-control in decision-making \\
\hline \multirow[t]{3}{*}{ Life and activity assessment } & Activities of daily living \\
\hline & Instrumental activities of daily living \\
\hline & Leisure activities and social activities \\
\hline \multicolumn{2}{|l|}{ In-depth health assessment } \\
\hline Physical health & $\begin{array}{l}\text { Impairment of physical health status, such as pain, discomfort, eyesight, } \\
\text { hearing, and skin condition }\end{array}$ \\
\hline \multirow[t]{6}{*}{ Activity/participation in daily and social life } & Cognition \\
\hline & Mobility \\
\hline & Self-care \\
\hline & Getting along with people \\
\hline & Life activities \\
\hline & Participation \\
\hline Environmental status & Housing and living environment \\
\hline
\end{tabular}

of the items. For example, a life and activity assessment is performed while showing various images that indicate each activity. The scores on Likert scales are indicated with common explanatory facial-expression icons. The health profiles are generated using text and also images, graphs, and an ICF model. This facilitates healthcare professionals, social workers, and community residents to share the assessment items and health profiles together through PC or mobile device screens.

\section{3) Evaluation and improvement of the system}

During a pretest of the first version of the system, the researchers noticed that the elderly participants experienced difficulties reading items on the screen, so this was addressed by making the text and images larger. The researchers also found that some words used in the system were difficult to understand for the general community residents, so this was addressed by inserting more rubrics to facilitate their understanding.

When the researchers implemented the pilot test of the fi- nal version, the healthcare professionals and social workers stated that the new assessment system simplified the assessment process in comparison to previous paper-based assessment processes. The community residents reported that they found it very convenient to be able to check their health and social needs comprehensively using a mobile phone, tablet, or laptop. One of the best aspects of the system was that they could see the assessment results on the screen immediately after completing the assessment process. The three experts from medical engineering and computer science who evaluated the appropriateness of the algorithms used to implement the CHSNA system considered the user interface, user experience, and system realization to be good.

\section{Discussion}

The CHSNA system was designed to evaluate the healthcare and social needs of community residents based on using an ICT-based system to help provide effective personcentered community care. We focused on making the system 
evidence-based, person-centered, and user-friendly during every step of its development and performed continuous evaluation to achieve this.

The researchers applied evidence-based knowledge by using the official ICF classification of the WHO [14] and reliable instruments. The assessment process using the CHSNA system and the obtained assessment results should enable healthcare professionals and social workers to implement evidence-based practice for community residents.

The researchers also included person-centered care (PCC) in the CHSNA system. The healthcare professionals, social workers, and community residents collaborated while assessing the needs of the community residents and planning care management by sharing the PC or mobile device screen. This will help to improve the quality of decision-making based on the preferences and values of community residents.

The CHSNA system has a user-friendly design. Based on self-reported questionnaires and focus-group interviews, the demands of the target users could be applied to the overall system design. The evidence for the successful design came from the target users providing positive feedback after they experienced using the system.

In conclusion, the CHSNA system is the first system developed using the ICF framework and based on ICT in Korea to help community residents, healthcare professionals, and social workers become involved in person-centered community care. This will help community residents comprehend their own unmet needs and participate in designing their own care plans with support from healthcare professionals and social workers.

\section{Conflict of Interest}

No potential conflict of interest relevant to this article was reported.

\section{Acknowledgments}

This work was supported by Community Business Development Program through the Korea Institute for Advanced of Technology (KIAT) funded by the Ministry of Trade, Industry, and Energy (No. P0004335).

\section{ORCID}

Myonghwa Park (http://orcid.org/0000-0002-0329-0010)

Eun Jeong Choi (http://orcid.org/0000-0001-9570-8340)

Miri Jeong (http://orcid.org/0000-0002-3334-4200)
Nayoung Lee (http://orcid.org/0000-0003-2577-0004)

Minjung Kwak (http://orcid.org/0000-0002-3853-4716)

Mihyun Lee (http://orcid.org/0000-0001-5700-3534)

Eun-Chung Lim (http://orcid.org/0000-0002-1352-5434)

Haesung Nam (http://orcid.org/0000-0003-0911-4576)

Dongil Kim (http://orcid.org/0000-0001-7425-7579)

Hanwool Ku (http://orcid.org/0000-0002-2668-7758)

Bong Seok Yang (http://orcid.org/0000-0003-4739-6738)

Junsik Na (http://orcid.org/0000-0002-3505-5779)

Joong Shik Jang (http://orcid.org/0000-0003-2791-880X)

Ji Young Kim (http://orcid.org/0000-0002-7104-0355)

Wonpyo Lee (http://orcid.org/0000-0003-3525-4011)

\section{References}

1. Organisation for Economic Cooperation and Development. Health at a glance 2011: OECD indicators. Paris, France: OECD Publishing; 2011.

2. Willard S, Cremers G, Man YP, van Rossum E, Spreeuwenberg M, de Witte L. Development and testing of an online community care platform for frail older adults in the Netherlands: a user-centred design. BMC Geriatr 2018;18(1):87.

3. De Vliegher K, Aertgeerts B, Declercq A, Milisen K, Sermeus W, Moons P. Shifting care from hospital to home: a qualitative study. Primary Health Care, 2015;25(9):2633.

4. Ministry of Health and Welfare. Implementation of social services (community care) based on the community [Internet]. Sejong, Korea: Ministry of Health and Welfare; 2018 [cited at 2019 Oct 15]. Available from: http://www.mohw.go.kr/react/al/sal0301vw.jsp? PAR_MENU_ID $=04 \& M E N U \_I D=0403 \& C O N T$ _ SEQ $=344177$ \&page $=1$.

5. Vlachantoni A, Shaw R, Willis R, Evandrou M, Falkingham J, Luff R. Measuring unmet need for social care amongst older people. Popul Trends 2011;(145):56-72.

6. Jung Y, Ko S, Kim EJ. A study on the effective chronic disease management. Seoul: Korea Institute for Health and Social Affairs; 2013.

7. World Health Organization. How to use the ICF: a practical manual for using the International Classification of Functioning, Disability and Health (ICF): exposure draft for comment. Geneva, Switzerland: World Health Organization; 2013.

8. Smith M, Epping-Jordan J. WHODAS II training manual: a guide to administration. Geneva, Switzerland: World Health Organization; 2000. 
9. Yun JS, Kim JM, Sin IS, Yang SJ, Jeong TG, Lee HY. Development of Korean version of World Health Organization Disability Assessment Schedule II (WHODAS II-K) in community dwelling elders. J Korean Neuropsychiatr Assoc 2004;43(1):86-92.

10. Bedirhan Ustun T, Chatterji S, Villanueva M, Bendib L, Celik C, Sadana R, et al. WHO multi-country survey study on health and responsiveness. Geneva, Switzerland: World Health Organization; 2001.

11. Ustun TB, Rehm J, Chatterji S, Saxena S, Trotter R, Room R, et al. Multiple-informant ranking of the disabling effects of different health conditions in 14 countries. Lancet 1999;354(9173):111-5.

12. Bedirhan Ustun T, Chatterji S, Mechbal A, Murrey CJ;
WHS Collaborating Groups. The world health surveys. In: Murrey CJ, Evans DB, editors. Health systems performance assessment: debates, methods and empiricism. Geneva, Switzerland: World Health Organization; 2003. p. 797-808.

13. Dernek B, Esmaeilzadeh S, Oral A. The utility of the International Classification of Functioning, Disability and Health checklist for evaluating disability in a community-dwelling geriatric population sample. Int J Rehabil Res 2015;38(2):144-55.

14. World Health Organization. International classification of functioning, disability and health: ICF. Geneva, Switzerland: World Health Organization; 2001. 